K

линико-морфологическая диагностика кожных проявлений реакции «трансплантат против хозяина»
А.Ю. Криволапова ${ }^{1}$, И.О. Смирнова², Е.в.
В. Лисукова ${ }^{1}$, И.
И.С. Моисеeв ${ }^{1}$, И.
И.Э. Белоусова ${ }^{3}$

B.В. Байков ${ }^{1}$

${ }^{1}$ ГБОУ ВПО «Первый Санкт-Петербургский государственный медицинский университет им. академика И.П. Павлова»: научно-исследовательский институт детской онкологии, гематологии и трансплантологии им. Р.М. Горбачевой 197022, Санкт-Петербург, ул. Льва Толстого, д. 6-8

2 Санкт-Петербургский государственный университет, медицинский фракультет 199106, Санкт-Петербург, 21-я линия В.0., д. 8а

${ }^{3}$ Военно-медицинская академия им. С.М. Кирова 194044, Санкт-Петербург, ул. Академика Лебедева, д. 6

Кожная реакция «трансплантат против хозяина» является опасным осложнением аллогенной трансплантации костного мозга, требующим быстрой и точной диагностики.

Цель. Изучить клинические особенности течения кожной формы реакции «трансплантат против хозяина»

и диффреренциально-диагностическое значение гистологических и иммуногистохимических признаков в биоптатах кожи при РТПХ

Материал и методы. Проведена сравнительная оценка клинических данных больных острой РТПХ (50 пациентов) и токсикодермией (10 пациентов). Исследованы патоморфологические и иммуногистохимические особенности в биоптатах кожи пациентов обеих групп: препараты окрашены гематоксилином и эозином, а также с помощью антител к CD3, CD20, CD4, CD8, F0XP3, CD56, CD1a, CD68.

Результаты. При оценке клинических данных значимых различий в группах выявлено не было. При морфологическом исследовании установлено, что количество эозинофилов, CD8+, CD1a+, CD3+, F0XP3+ клеток, доля FOXP3+ клеток среди Т-лимфоцитов оказалось достоверно больше в группе токсикодермии. Заключение. Для диагностики острой РТПХ необходима комплексная оценка клинических данных и результатов морфологического исследования с анализом популяционного состава инсрильтрата

Ключевые слова: реакция «трансплантат против хозяина», РТПХ, кожа, иммуногистохимия.

Контактная информация: akrivolapova@gmail.com. Вестник дерматологии и венерологии 2015; (3): 96 —103. 


\title{
Clinical and morphological diagnostics of skin manifestations in case of graft-versus-host disease
}

\author{
A.Yu. Krivolapova', I.O. Smirnova², Ye.V. Lisukova', I.S. Moiseyev', I.E. Belousova ${ }^{3}$, \\ V.V. Baikov ${ }^{1}$ \\ ${ }^{1}$ Saint Petersburg State Medical University \\ L. Tolstogo str., 6-8, St. Petersburg, 197022, Russia \\ 2 Saint Petersburg State University \\ 21-ya Liniya V. 0., 8A, St. Petersburg, 199106, Russia \\ ${ }^{3}$ Military Medical Academy named after S.M. Kirov Ministry of Defense of the Russian Federation \\ Akademika Lebedeva str., 6, St. Petersburg, 194044, Russia
}

The graft-versus-host disease is a life-threatening complication of allogeneic bone marrow transplantation, which demands fast and reliable diagnostics.

Goal. To study clinical features of the graft-versus-host disease as well as differential and diagnostic value of histological and immunohistochemical signs in skin biopsy samples in case of graft-versus-host disease (GvHD).

Materials and methods. The authors made a comparative assessment of clinical data available for patients suffering from acute GvHD (50 patients) and toxic dermatitis (10 patients). Skin biopsy samples taken from patients from both groups underwent postmortem and immunohistochemistry examinations: the drugs were stained with hematoxylin and eosin as well as by using anti-CD3, CD20, CD4, CD8, FOXP3, CD56, CD1a and CD 68 antibodies.

Results. Based on the results of clinical data assessments, no significant differences in the groups were revealed. The morphological examination revealed that the number of eosinophils, CD8+, CD1a+, CD3+ and FOXP3+ cells and share of FOXP3+ cells among T lymphocytes was higher in the group with toxic dermatitis.

Conclusion. An integrated assessment of clinical data and morphological examination results accompanied by the analysis of the population composition of the infiltrate is needed to diagnose the acute GvHD.

Key words: graft-versus-host disease, GuHD, skin, immunohistochemistry. 
Трансплантация костного мозга (ТKM) - современный высокотехнологичный метод лечения онкологических, гематологических и ревматологических заболеваний. По данным Всемирной ассоциации доноров костного мозга, ежегодно в мире осуществляется до 150000 TKM, значительная часть которых является аллогенными. Реакция «трансплантат против хозяина» (РТПХ), осложняющая более половины всех аллогенных ТKM (аллоТКМ), представляет собой опасное для жизни системное заболевание с поражением кожи и слизистых оболочек, а также ряда внутренних органов (легких, желудочно-кишечного тракта, печени) [1]. В процессе приживления трансплантата донорские Т-лимфоциты взаимодействуют с дендритными клетками реципиента, что на фоне ко-стимуляции через TLR (toll-подобные рецепторы) продуктами бактериального и тканевого распада приводит к формированию клонов аллореактивных Т-цитотоксических лимфоцитов. Наличие таких клонов является важнейшим условием развития РТПХ. Максимально рано начатое лечение РТПХ позволяет снизить летальность после аллоТКМ, поэтому очень важна точная ранняя диагностика этого процесса [2].

РТПХ, развернувшаяся в первые 100 дней после аллоТКМ, обычно классифицируется как острая РТПХ (кроме острой и хронической РТПХ в настоящее время выделяют overlap-синдром, который может иметь признаки и острой, и хронической РТПХ вне зависимости от сроков развития). При острой РТПХ наиболее часто поражаются кожа, желудочно-кишечный тракт и печень. Клинические симптомы проявляются пятнистопапулезными высыпаниями на коже, нередко с буллезными элементами, спастическими болями в животе, тошнотой, рвотой, диареей, тяжестью в правом подреберье. Клиническая картина РТПХ разнообразна, наиболее часто РТПХ начинается именно с кожныХ проявлений [3]. Как правило, высыпания представлены зудящими, иногда болезненными и склонными к слиянию эритемато-сквамозными элементами, появление которых нередко сопровождается повышением температуры тела. Кожный процесс при острой РТПХ может быть локализованным или, гораздо чаще, распространенным. Клинически различают 4 степени кожной формы острой РТПХ, в основе классификации лежит оценка площади поражения кожного покрова, характер высыпных элементов (таблица) [4].

В послеоперационном периоде пациенты, перенесшие аллоТКМ, получают цитостатики, иммуносупрессанты, антибиотики, противовирусные и антимикотические препараты, что обусловливает высокий риск развития токсикодермии [5]. Клинически высыпания токсико-аллергической природы трудно дифрференцировать с острой РТПХ, поэтому при появлении сыпи выполняется диагностическая биопсия кожи. При патоморфологическом исследовании оценивают изменения эпидермиса, степень повреждения дермоэпидермального соединения, характер, расположение и клеточный состав воспалительного инфильтрата в дерме. Особое внимание уделяют состоянию придатков кожи: в ряде случаев признаки иммунообусловленного повреждения кератиноцитов более выражены в придатках, чем в покровном эпителии [6]. Данные немногочисленных исследований, посвященных изучению специфических патоморфологических признаков кожной фрормы РТПХ, нередко противоречивы и неоднозначны $[7,8]$. Тем не менее в мировой клинической практике гистологическое исследование кожных биоптатов при подозрении на РТПХ считается необходимым и является наиболее веским аргументом при верификации диагноза.

Цель исследования - изучить клинические особенности течения кожной формы реакции «трансплантат против хозяина» и дифференциально-диагностическое значение гистологических и иммуногистохимических признаков в биоптатах кожи при РТПХ.

\section{Материал и методы}

Материалом исследования были 60 пациентов: группу исследования составили 50 больных с кожной формой острой РТПХ (медиана возраста 27), группу сравнения - 10 больных с токсикодермией (медиана возраста 62), не имевших в анамнезе аллоТКМ. Диагноз устанавливался на основании стандартизированных международных критериев [9], гистологическое заключение по биоптату кожи формулировалось на основании консенсуса двух экспертов-патологоанатомов

\begin{tabular}{lc}
\hline & Площадь пораженного кожного покрова \\
\hline Степень 0 & 0 \\
\hline Степень 1 & $25-50$ \\
\hline Степень 2 & Генерализованная эритродермия \\
\hline Степень 3 & Генерализованная эритродермия с формированием пузырей и явлениями эпидермолиза \\
\hline Степень 4 &
\end{tabular}


(ИБ и ВБ). Для группы РТПХ ретроспективно были изучены карты стационарных больных: учитывали пол и возраст пациентов, первичный диагноз, наличие клинико-гематологической ремиссии на момент аллоТКМ, степень родства донора костного мозга, режим кондиционирования, сроки развития РТПХ, клиническую степень тяжести РТПХ по Glucksberg, характер элементов кожной сыпи, наличие температурной реакции, вовлечение внутренних органов, исход заболевания. Для группы токсикодермии также ретроспективно были изучены карты амбулаторных больных, где учитывали пол и возраст пациентов, распространенность высыпаний, характер элементов кожной сыпи и наличие температурной реакции. В гистологических препаратах кожных биоптатов, окрашенных гематоксилином и эозином, оценивали наличие или отсутствие вакуольной дистрофии клеток покровного эпителия, апоптоза клеток придатков кожи, спонгиоза, паракератоза, эозинофильных гранулоцитов в клеточном инфильтрате в дерме, апоптоз клеток эпителия придатков, а также количество некротизированных кератиноцитов с сателлитными клетками (Satellite cell necrosis [SCN]) - групп клеток, состоящих из апоптотически измененного кератиноцита в окружении не менее чем двух интраэпидермальных лимфоцитов, - в эпидермисе в 10 полях зрения (об. 40 ок. 10× X 20 мм). Для оценки популяционного состава инфильтрата проводилось иммуногистохимическое исследование с использованием мышиных моноклональных антител к маркерам В-лимфоцитов (CD20 - клон L26, DAKO), Т-лимфоцитов (CD4 - клон 4B12, NovoCastra; CD8 - клон C8/144B, DAKO), клеток Лангерганса (CD1a - клон MTB1, Immunotech), макрофрагов (CD68 - клон KP1, DAKO), NK-клеток (CD56 клон 56C04, Thermoscientific); кроличьих моноклональных антител к маркеру Т-регуляторных лимфоцитов (FOXP3 - клон SP97, Spring Bioscience) и кроличьих поликлональных к маркеру Т-лимсоцитов (CD3 DAKO).

Оценивалось количество окрашенных клеток В 10 полях зрения (об. 40 ок. 10× X 20 мм), а также расчетный показатель доли FOXP3+ клеток среди всех Т-лимфоцитов. Полученные данные были обработаны с помощью программного пакета IBM SPSS Statistics, достоверность различий между группами оценивалась с помощью критериев $\chi^{2}$ (хи-квадрат) и Манна - Уитни. Результаты для качественных признаков представлены в виде доли (в процентах). Для количественных параметров в каждой группе определены среднее значение (математическое ожидание) и среднеквадратическое отклонение. Различия считались достоверными при значении $p<0,05$.

\section{Результаты исследования}

Среди 50 пациентов с кожной формой острой РТПХ 26 больных были мужского пола и 24 женского. Медиана возраста составила 27 лет. 42\% пациентов страдали острым миелобластным лейкозом, 38\% острым лимфобластным (всего больных с острыми лейкозами 80\%). Из всех пациентов с острой РТПХ 6\% пациентов имели первичный диагноз миелодиспластического синдрома, 6\% - лимфомы, 4\% - апластической анемии, 2\% - хронического миелоидного лейкоза и $2 \%-$ хронического лимфоцитарного лейкоза. На момент проведения аллоТКМ большинство больных (52\%) находилось в клинико-гематологической ремиссии. У $30 \%$ пациентов аллоТКМ была родственной, 70\% больных имели неродственного донора. Аблативный режим кондиционирования был использован в $48 \%$ случаев. У $46 \%$ больных острая РТПХ развилась в течение первых 30 дней посттрансплантационного периода, у 54\% - в период с +31 по +100 день. Клинически у $52 \%$ больных развилась острая РТПХ 1-2-й степени: высыпания носили преимущественно распространенный характер, локализовались на коже конечностей и/или туловища, были представлены множественными отечными эритематозными пятнисто-папулезными элементами, от 3 до 15 мм в диаметре, с относительно четкими границами, склонностью к слиянию, шелушением на поверхности (рис. 1). У четырех пациентов с поражением второй степени наблюдались геморрагические высыпания, у двух больных - формирование пузырей (рис. 2). У 48\% тяжесть РТПХ достигала 3-4-й степени: высыпания захватывали большую часть кожного покрова, представляли собой сливные ярко-эритематозные очаги, с формированием буллезных элементов у 7 пациентов (рис. 3). Температурная реакция наблюдалась у 68\% больных. У $28 \%$ пациентов было выявлено поражение внутренних органов, связанное с РТПХ: 18\% страдали острой РТПХ с поражением желудочно-кишечного тракта

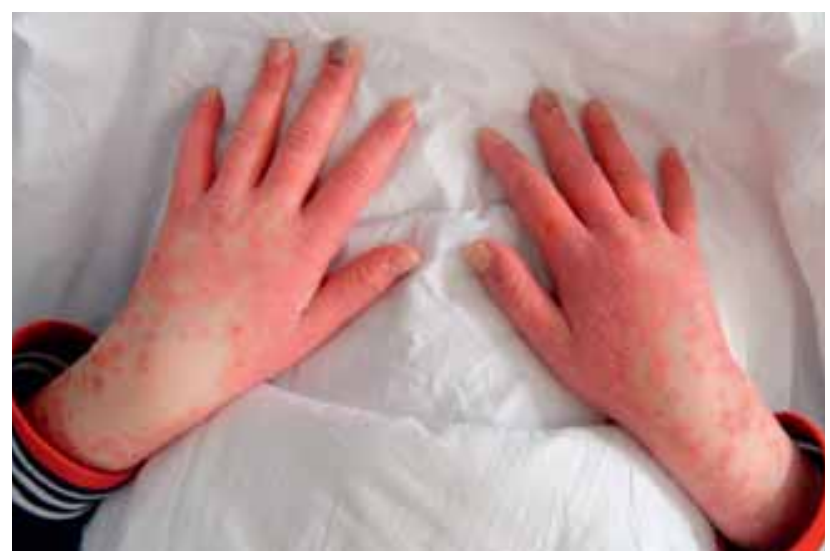

I РТПХ степени 1 по Glucksberg (площадь Рис. 1. поражения кожного покрова до 25\%: яркоэритематозная пятнисто-папулезная сыпь, среднепластинчатое шелушение) 
и 10\% - острой РТПХ с поражением печени. По окончании госпитализации 48\% пациентов продолжали болеть, 32\% выписаны с улучшением и 20\% умерли. Среди пациентов с токсико-аллергическими реакциями $60 \%$ были мужского пола и 40\% женского. Медиана возраста составила 62 года. У 70\% пациентов высыпания носили распространенный характер, захватывали до 50\% кожного покрова и были представлены пятнисто-папулезными эритематозными элементами от 2 до 10 мм в диаметре с шелушением на поверхности и выраженной склонностью к слиянию. У двух больных были выявлены локализованные буллезные элементы, у одного пациента доминировали геморрагические высыпания. Повышение температуры тела наблюдалось у 20\% пациентов группы токсикодермии. Летальных исходов зафиксировано не было.

При оценке морфологических параметров в кожных биоптатах больных РТПХ в сравнении с группой токсикодермии выявлены следующие различия. В группе РТПХ достоверно чаще обнаруживался апоптоз кератиноцитов в эпителии придатков кожи (66 и 10\% соответственно, $p<0,002$ ). Эозинофильные гранулоциты были обнаружены в дермальном инфрильтрате всех пациентов группы сравнения (100\%) и в дермальном инфильтрате только 6 пациентов группы РТПХ (12\%), $p<0,001$. Вакуольная дистрофия эпидермоцитов наблюдалась чаще в группе РТПХ (72\%), чем в группе токсикодермии (40\%), $p=0,05$. Количество некротизированных эпидермоцитов с сателлитными клетками - SCN (рис. 4) оказалось достоверно больше в группе РТПХ $(6,6 \pm 3,7)$, чем в группе сравнения $(1,6 \pm 1,5), p<0,001$. При оценке популяционного состава инфильтрата выявлено, что количество CD3+ клеток в группе токсикодермии достоверно превышает данный показатель в группе РТПХ (805,0 \pm 400,0 и 160,8 $\pm 86,7$ соответственно), $p<0,001$. FОХР3+ клетки достоверно чаще встречались в группе токсикодермии $(225,4 \pm 114,9$; при РТПХ - 5,02 \pm 3,7, $p<0,001$ ) (рис. 5, 6). Доля FOXP3+ клеток от всех CD3+ клеток также была больше в группе токсикодермии

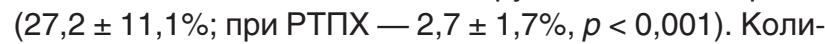
чество CD1a+ клеток было достоверно больше в эпидермисе у пациентов с токсикодермией $(217,5 \pm 178,6)$, чем в группе РТПХ $(41,4 \pm 32,2), p<0,001$. Среднее количество CD8+ клеток в дермальном инфильтрате пациентов с РТПХ составило 33,5 \pm 33,3, что оказалось достоверно меньше количества CD8+ клеток в группе сравнения $(262,0 \pm 159,3), p<0,001$. Группы наблюдения не различались достоверно по таким параметрам, как наличие спонгиоза, паракератоза, а также количество CD4+, CD56+ и CD68+ клеток.

\section{Обсуждение}

Характер элементов кожной сыпи и степень распространенности патологического процесса не позволяют провести дифференциальную диагностику острой

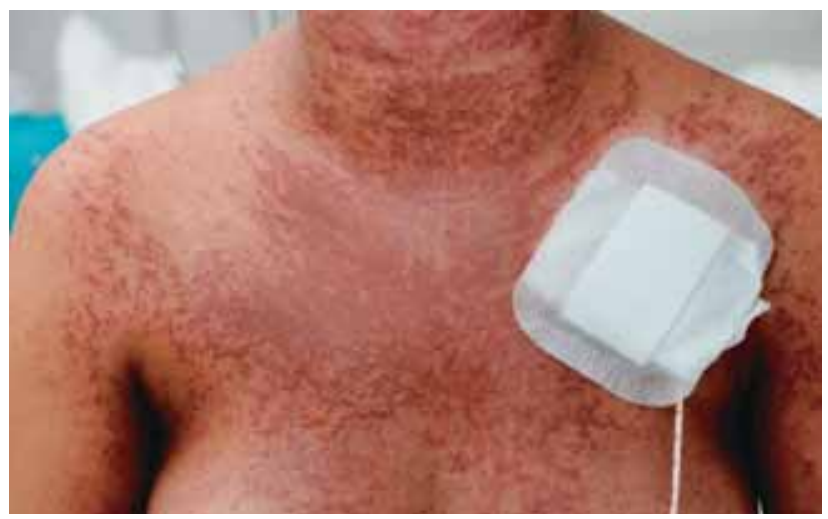

РТПХ степени 2 по Glucksberg (площадь

Рис. 2. поражения 25-50\% кожного покрова: геморрагические высыпания, формирование пузырей)

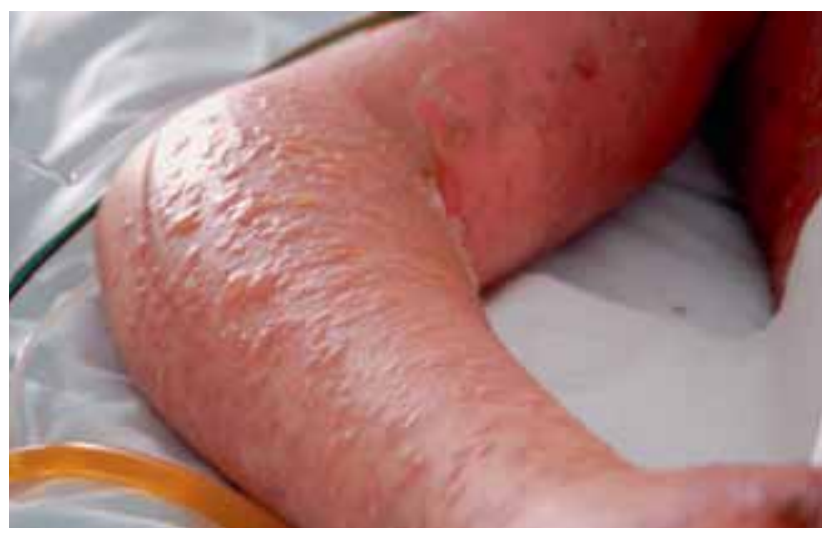

Рис. 3. РТПХ степени 4 по Glucksberg (эритродермия с явлениями эпидермолиза)

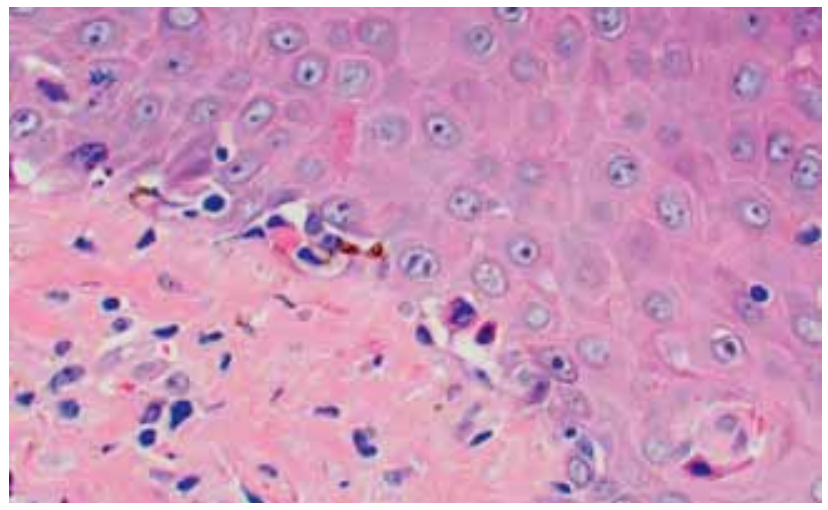

Рис. 4. Некроз эпидермоцитов с сателлитными клетками (об. 60 ок. 10 , окраска гематоксилин-эозин) 


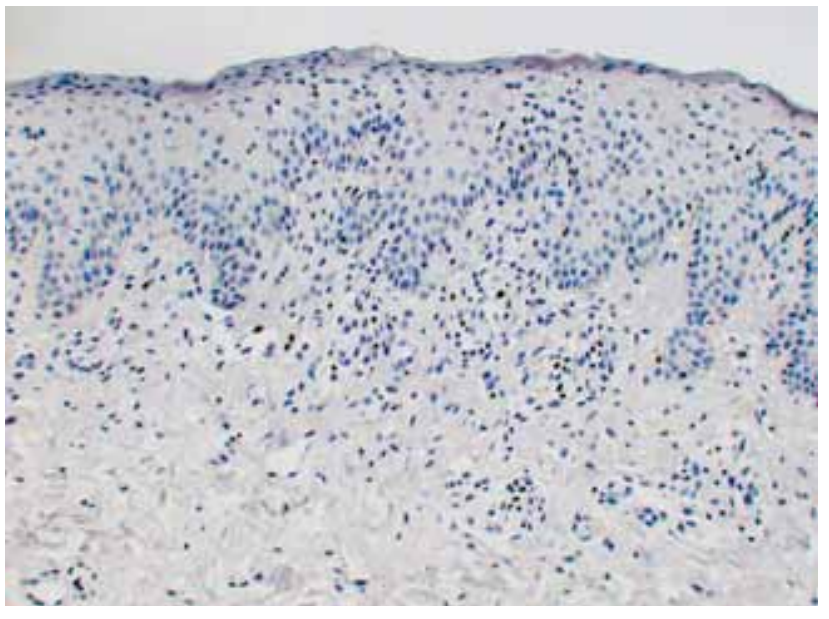

Рис. 5. FОХР3+ клетки при РТПХ (об. 20 ок. 10, иммуногистохимическая реакция)
РТПХ и токсико-аллергических реакций. Клиническая картина при токсикодермии проявляется разнообразными элементами кожной сыпи и характеризуется полиморфизмом: пятнисто-папулезные элементы, как правило, ярко-эритематозной окраски, с шелушением на поверхности, располагаются диссеминированно по кожному покрову и склонны к слиянию. Иногда на эритематозном фоне могут выделяться элементы геморрагического, уртикарного, буллезного характера. В настоящем исследовании в группе пациентов с токсикодермией у двух третей больных была выявлена макуло-папулезная сыпь, гораздо реже обнаруживались геморрагические высыпания и буллезные элементы. При исследовании пациентов с РТПХ клиническая картина в большинстве случаев также характеризовалась пятнисто-папулезными высыпаниями. Геморрагическая сыпь наблюдалась в единичных случаях.

Значимых дифрференциально-диагностических признаков не выявлено и при оценке анамнестических данных больных с РТПХ. В группе РТПХ преобладали пациенты с острыми лейкозами, что, вероятно, связано с общей тенденцией отбора пациентов на TKM, где наибольшую долю составляют больные молодого возраста с бластными лимфо- и миелопролиферативными заболеваниями [10]. Следует отметить преобладание среди больных с РТПХ пациентов с неродственной аллоТКМ, что является достоверным фрактором риска развития РТПХ [3].

При морфологическом исследовании и анализе биоптатов пациентов обеих групп был выявлен ряд различий, самостоятельная значимость которых неочевидна. Так, вакуольная дистрофия кератиноцитов базального слоя наблюдается при ряде других дерматологических заболеваний и не является специфичным признаком РТПХ $[7,11]$. Наличие кератиноцитов

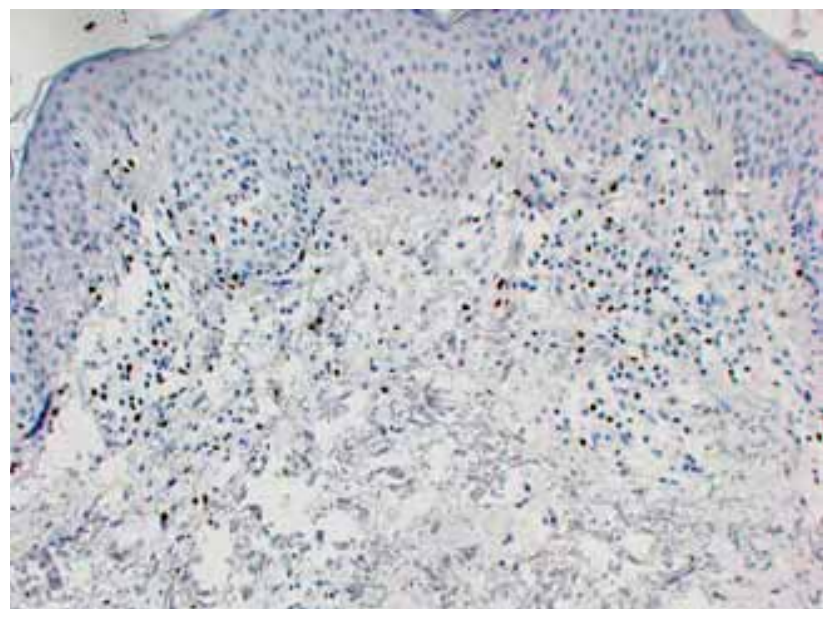

Рис. 6. FОХР3+ клетки при токсикодермии (об. 20 ок. 10

с признаками апоптоза, в частности SCN, учитывается как высокочувствительный, но неспецифичный критерий диагностики РТПХ, который обычно используют в качестве критерия тяжести реакции $[12,13]$.

Данные анализа популяционного состава клеточного инфильтрата в целом согласуются с современными представлениями о патогенезе РТПХ. Количество CD3+ (Т-) клеток, а также количество FOXP3+ и CD8+ клеток при РТПХ оказалось значительно меньшим, чем при токсикодермии. В настоящее время развитие РТПХ связывают прежде всего с дисбалансом эффректорных и регуляторных фрункций Т-лимфоцитов, возникающим при (биологически обоснованном) распознавании донорскими Т-клетками антигенов реципиента как чужеродных [14]. Полагают, что одновременная пролиферация и активация Т-регуляторных клеток могла бы контролировать избыточную активацию Т-эффекторов и ограничивать клинически неблагоприятные последствия этого процесса массивный выброс провоспалительных цитокинов. Т-регуляторные клетки имеют фенотип CD3+ CD4+, CD25+, FOXP3+ и удовлетворительно выявляются при использовании FOXP3 в качестве единственного маркера [15]. Ранее показано, что количество FOXP3+ Т-лимфоцитов у больных РТПХ в коже меньше, чем у пациентов с посттрансплантационными дерматозами, не связанными с РТПХ, но достоверно больше, чем у здоровых людей [16], и этот показатель обратно пропорционален тяжести проявлений и прогнозу РТПХ [17]. В то же время количество Т-регуляторных клеток не позволяет прогнозировать рецидив основного заболевания [18]. В условиях относительной бедности клеточного инфильтрата количество (и долю) Т-регуляторных лимфоцитов в биоптатах кожи оценивать сложно, особенно в ранние сроки после ТКМ. 
Количество CD3+ и CD8+ клеток в инфильтрате у больных с РТПХ было меньшим, чем при токсикодермии. Однако индивидуальные колебания этих показателей были очень велики. Известно, что различные типы несоответствия в системе главного комплекса гистосовместимости пары донор-реципиент ведут к разным вариантам непропорционального восстановления гемопоэза [3]. Это обстоятельство ограничивает диагностическую значимость обнаруженных различий, несмотря на удовлетворительную математическую достоверность.

Клетки Лангерганса являются антиген-представляющими клетками кожи, они играют значимую роль в иммуноопосредованных воспалительных реакциях. Существуют основания полагать, что наибольшее значение в инициации РТПХ имеет презентация клетками Лангерганса не столько нормальных антигенов, сколько антигенов, поврежденных в ходе химиолучевой терапии. Подобная активность может сопровождаться увеличением количества CD1a позитивных клеток в целом [19]. В то же время в ряде исследований не выявлено количественных и качественных различий антиген-представляющих клеток у больных с РТПХ в сравнении с контрольной группой [20, 21].

Таким образом, ни один из морфологических признаков не позволяет уверенно разграничить пораже- ния кожи при РТПХ и токсико-аллергических реакциях. В то же время на основании проведенного исследования можно сорормировать группы признаков, совокупность которых имеет значение в диффреренциальной диагностике этих состояний. В пользу РТПХ свидетельствует сочетание таких признаков, как значительное количество SCN клеток в эпидермисе, апоптоз кератиноцитов придатков кожи, малое количество FOXP3+ лимфоцитов среди всех Т-лимфоцитов при незначительном количестве CD1a+ клеток в эпидермисе. Ecли же в препарате отсутствуют явления апоптоза кератиноцитов придатков кожи, встречается много FOXP3+ и CD4+ лимфоцитов, имеется значительное число CD1a+ клеток в эпидермисе и одновременно присутствуют эозинофильные гранулоциты в дермальном инфильтрате, то дифференциальный диагноз склоняется в пользу токсико-аллергической реакции. Значимость указанных совокупностей признаков в дифференциальной диагностике РТПХ и токсико-аллергических реакций была подтверждена математически.

\section{Заключение}

Для диагностики острой РТПХ необходима комплексная оценка клинических данных и результатов морфологического исследования с анализом популяционного состава инфрильтрата. І
1. Shulman H., Kleiner D., Lee S. et al. Histopathologic Diagnosis of Chronic Graft-versus-Host Disease: National Institutes of Health Consensus Development Project on Criteria for Clinical Trials in Chronic Graft-versus-Host Disease: II. Pathology Working Group Report. Biology of Blood and Marrow Transplantation. 2006; 12 (1): $31-47$.

2. Marra D.E., Mckee P.H., Nahiem P. Tissue eosinophils and the perils of using skin biopsy specimens to distinguish between drug hypersensitivity and cutaneous graft-versus-host disease. Journal of the American Academy of Dermatology. 2007; 51 (4): 543-546.

3. Jacobsohn D.A., Vogelsang G. Acute graft versus host disease. Orphanet journal of Rare Diseases. 2007; 4 (2): 35.

4. Glucksberg H., Storb R., Fefer A. et al. Clinical manifestations of graft-versus-host disease in human recipients of marrow from $\mathrm{HL}-\mathrm{A}$-matched sibling donors. Transplantation. 1974; 18: 295-304.

5. Byun H.J., Yang J.I., Kim B.K. Clinical differentiation of acute cutaneous graft-versus-host disease from drug hypersensitivity reactions. Journal of the American Academy of Dermatology. 2011; 65 (4): 726

\section{Литература}

6. Heldal D., Brinch L., Evensen S.A. et al. Skin biopsies for early diagnosis and prognosis of graft-versus-host disease in recipients of allogeneic stem cells from blood or bone marrow. Bone Marrow Transplantation. 2004; 34 (4): $345-350$.

7. Ziemer M., Haeusermann P., Janin A. et al. Histopathological diagnosis of graft-versus-host disease of the skin — an interobserver comparison. Journal of the European Academy of Dermatology and Venereology. 2014 Jul; 28 (7): 915—924.

8. Zhou Y., Barnett M.J., Rivers J.K. Clinical significance of skin biopsies in the diagnosis and management of graft-versus-host disease in early postallogeneic bone marrow transplantation. Archives of dermatology. 2000; 136 (6): 717-721.

9. Przepiorka D., Weisdorf D., Martin P. et al. 1994 Consensus Conference on Acute GVHD Grading. Bone Marrow Transplant. 1995; 15 (6): $825-8$.

10. National Cancer Institute - PDQ Cancer Information Summaries. Adult Acute Myeloid Leukemia Treatment. 2014 Mar.

11. Weedon D. Weedon's Skin Pathology. 3rd ed. London: Churchill Livingstone Elsevier. 2010: 36-37.
12. Lerner K.G., Kao G.F., Storb R. et al. Histopathology of graft-vs.-host reaction (GvHR) in human recipients of marrow from $\mathrm{HL}-\mathrm{A}$-matched sibling donors. Transplantation Proceedings. 1974; 6 (4): $367-371$.

13. Murphy G.F., Korngold R. Significance of selectively targeted apoptotic rete cells in graft-versus-host disease. Biology of Blood and Marrow Transplantation. 2004; 10 (6): 357-365.

14. Yan B., Da W. CD4+CD25+ regulatory T cells and their function in graft-versus-host diseasereview. Journal of experimental hematology Chinese Association of Pathophysiology. 2006; 14 (2): 408-412.

15. Rezvani K., Mielke S., Ahmadzadeh M. et al. High donor FOXP3-positive regulatory T-cell (Treg) content is associated with a low risk of GVHD following HLA-matched allogeneic SCT. Bllod. 2006; 108 (4): 1291-1297.

16. Li Q., Zhai Z., Xu X. et al. Decrease of CD4+CD25+ regulatory T cells and TGF- at early immune reconstitution is associated to the onset and severity of graft-versus-host disease following allogeneic haematogenesis stem cell transplantation. Leukemia Research. 2010; 34 (9): 1158-1168. 
17. Fondi C., Nozolli C., Benemei S. et al. Increase in FOXP3+ Regulatory T Cells in GVHD Skin Biopsies Is Associated with Lower Disease Severity and Treatment Response. Biology of Blood and Marrow Transplantation. 2009; 15 (8): 938-947.
18. Wolf D., Wolf A.M., Fong D. et al. Regulatory T-cells in the graft and the risk of acute graftversus-host disease after allogeneic stem cell transplantation. Transplantation. 2007 Apr 27; 83 (8): 1107-13

19. Chakraverty R., Sykes M. The role of antigenpresenting cells in triggering graft-versus-host disease and graft-versus-leukemia. Blood. 2007; 110: 9-17.
20. Andani R., Robertson I., Macdonald K.P. et al. Origin of Langerhans cells in normal skin and chronic GVHD after hematopoietic stem-cell transplantation. Experimental Dermatology. 2014; 23 (1): 75-77.

21. Li H., Kaplan D., Matte-Martone C. et al. Langerhans cells are not required for graft-versus-host disease. Blood. 2011; 117 (2): 697-707.

об авторах:

А.Ю. Криволапова — интерн кафедры патологической анатомии ГБОУ ВПО ПСПбГМУ им. акад. И.П. Павлова Минздрава России

И.О. Смирнова - д.м.н., профессор кафедры инфекционных болезней, эпидемиологии и дерматовенерологии медицинского факультета Санкт-Петербургского государственного университета

Е.В. Лисукова — к.м.н., старший научный сотрудник научно-исследовательского института детской онкологии, гематологии и трансплантологии им. Р.М. Горбачевой, Санкт-Петербург

И.С. Моисеев — к.м.н., зав. лабораторией трансплантологии научно-исследовательского института детской онкологии, гематологии и трансплантологии им. Р.М. Горбачевой, Санкт-Петербург

И.Э. Белоусова - д.м.н., профрессор кафедры кожных и венерических болезней Военно-медицинской академии

им. С.М. Кирова, Санкт-Петербург

В.В. Байков - д.м.н., профессор кафедры патологической анатомии ГБОУ ВПО ПСПбГМУ им. акад. И.П. Павлова Минздрава России, сотрудник научно-исследовательского института детской онкологии, гематологии и трансплантологии

им. Р.М. Горбачевой, Санкт-Петербург

\section{Конфликт интересов}

Авторы заявляют об отсутствии потенциального конфрликта интересов, требующего раскрытия в данной статье 